\title{
Aspergillus fumigatus germ tube growth and not conidia ingestion induces expression of inflammatory mediator genes in the human lung epithelial cell line A549
}

Correspondence

Stéphane Bretagne

bretagne@univ-paris12.fr

Received 28 July 2008

Accepted 20 October 2008

\author{
Anne-Pauline Bellanger, ${ }^{1}$ Laurence Millon, ${ }^{1}$ Khaled Khoufache, ${ }^{2}$ \\ Danièle Rivollet, ${ }^{2}$ Ivan Bièche, ${ }^{3}$ Ingrid Laurendeau, ${ }^{3}$ Michel Vidaud, ${ }^{3}$ \\ Françoise Botterel $^{2}$ and Stéphane Bretagne ${ }^{2}$ \\ 1 UMR 6249 CNRS, Laboratoire de Parasitologie-Mycologie, Hôpital Jean Minjoz, Besançon, France \\ ${ }^{2}$ UMR BIPAR 956, Laboratoire de Parasitologie-Mycologie, Hôpital Henri Mondor and Université \\ Paris-Est, Créteil, France \\ ${ }^{3}$ UMR INSERM 745, Université Paris Descartes, Faculté des Sciences Pharmaceutiques et \\ Biologique, Paris, France
}

\begin{abstract}
Inhalation of conidia is the main cause of invasive pulmonary aspergillosis (IPA) and the respiratory epithelium is the first line of defence. To explore the triggering factor for the inflammatory response to Aspergillus fumigatus, the species mainly responsible for IPA, this study analysed the differential expression of three inflammatory genes in A549 cells after challenge with live and killed conidia. The influence of steroids, one of the main risk factors for developing IPA, was also investigated. Quantification of mRNAs of the inflammatory mediator genes encoding interleukin (IL)-8, tumour necrosis factor (TNF)- $\alpha$ and granulocyte-monocyte colony-stimulating factor (GMCSF) was carried out using real-time PCR. Ingestion rates were studied for the conidia of $A$. fumigatus and Penicillium chrysogenum using a fluorescence brightener. Similar results were obtained for both species, with ingestion rates ranging from 35 to $40 \%$. Exposure of A549 cells to live $A$. fumigatus conidia only induced a four- to fivefold increase in the mRNA levels of the three genes, starting $8 \mathrm{~h}$ after the initial contact. Both inactivation of live $A$. fumigatus conidia and treatment by dexamethasone $\left(10^{-7} \mathrm{M}\right)$ prevented the overexpression of TNF- $\alpha$, IL- 8 and GMCSF. Fungal growth, rather than conidia ingestion, appears to be the main stimulus for the production of inflammatory mediators by epithelial cells, and this production is inhibited by steroid therapy. These results underline the role that the epithelium plays in the innate response against IPA.
\end{abstract}

\section{INTRODUCTION}

Invasive pulmonary aspergillosis (IPA) is an opportunistic infection whose incidence is increasing at the same rate as the number of severely immunocompromised patients (Lin et al., 2001). Neutropenia and high-dose steroid treatments are the main risk factors for IPA, and these underline the importance of an appropriate inflammatory response if fungal invasion is to be avoided. Most authors stress the important roles that alveolar macrophages and neutrophils play in controlling infection (Romani, 2004; Walsh et al., 2005). The release of innate immune-related molecules from professional phagocytic cells in the course of

Abbreviations: ANOVA, analysis of variance; $C_{t}$, cycle threshold; GMCSF, granulocyte-monocyte colony-stimulating factor; IL, interleukin; IPA, invasive pulmonary aspergillosis; TNF, tumour necrosis factor.
Aspergillus fumigatus infection has been widely studied (Meier et al., 2003; Pylkkanen et al., 2004; Cortez et al., 2006). However, the respiratory epithelium is the first tissue that inhaled conidia encounter, and it probably participates in the efficient coordinated response against IPA. In animal models of IPA, most inhaled conidia are trapped in the upper respiratory tract, and the respiratory epithelium coordinates with alveolar macrophages (Stephens-Romero et al., 2005).

A few studies have investigated the production of inflammatory mediators by studying the human lung epithelial cell line A549 after stimulation with moulds or mould extracts (Borger et al., 1999; Kauffman et al., 2000; Huttunen et al., 2003; Zhang et al., 2005; Tai et al., 2006). These studies have focused on fungi as the source of allergens, and on species other than A. fumigatus, which are 
often more allergenic (Kauffman et al., 2000). To our knowledge, there are no reports on the response of A549 cells to germinating A. fumigatus or on comparisons with other mould species. Spores of other mould species usually outnumber A. fumigatus conidia in inhaled air, although $A$. fumigatus is the main aetiological agent of IPA. Therefore, differences observed between A. fumigatus conidia and the spores of other species after the challenge of respiratory epithelium could help explain why A. fumigatus is a frequently encountered aetiological agent of invasive infection.

The aim of our study was to investigate the early inflammatory signals in airway epithelial cells after exposure to A. fumigatus conidia using real-time quantitative PCR for reliable quantification of expression of selected inflammatory mediator genes (Stordeur et al., 2002; Asselah et al., 2005). We used in our study Penicillium chrysogenum as a control for conidia ingestion (Botterel et al., 2008). P. chrysogenum is a mould that is highly predominant in the environment, with a conidial size $(3-4 \mu \mathrm{m}$ diameter) similar to that of A. fumigatus. Although P. chrysogenum can germinate at $37{ }^{\circ} \mathrm{C}$ (de Hoog et al., 2000), this fungus is rarely responsible for invasive disease. We also aimed to explore the effect of steroids on the development of the inflammatory response of the A549 cell line after challenge with live A. fumigatus conidia.

\section{METHODS}

Fungal strains. A. fumigatus strain IP 2279.94 and $P$. chrysogenum strain IP 1652.86 (both from the Pasteur Institute) were grown in $2 \%$ malt agar tubes (Bio-Rad) for 7 days at their optimal growth temperature: 37 and $27{ }^{\circ} \mathrm{C}$ for A. fumigatus and $P$. chrysogenum, respectively. The conidia were harvested with $\mathrm{PBS} / 0.01 \%$ Tween 20 and $1 \mathrm{ml}$ of conidia suspension $\left(10^{6} \mathrm{ml}^{-1}\right)$ was used to seed the wells containing A549 cells. For some experiments, conidia were inactivated either chemically with $10 \%(\mathrm{v} / \mathrm{v})$ formaldehyde or by heating at $100{ }^{\circ} \mathrm{C}$ in water for $1 \mathrm{~h}$, and were resuspended in culture medium at $10^{6}$ conidia $\mathrm{ml}^{-1}$.

Cell lines. The alveolar epithelial cell line A549 was purchased from the German Collection of Micro-organisms and Cell Cultures (DSMZ) and cultured in Dulbecco's modified Eagle's medium (DMEM; Invitrogen), with $10 \%$ heat-inactivated fetal bovine serum (Biowest) and $25 \mu \mathrm{g}$ gentamicin $\mathrm{ml}^{-1}$ (Sigma-Aldrich). The medium was changed every 2 days and cells were confluent after 5 days. Cell cultures were checked for the presence of Mycoplasma spp. every month using the Venor GeM Mycoplasma Detection PCR kit (BioValley). A549 cells were cultivated in 24-well microtitre plates (VWR). Confluent A549 cells $\left(\sim 5 \times 10^{6}\right.$ cells per well $)$ were seeded with conidial suspensions. Plates were centrifuged for $5 \mathrm{~min}$ at 1500 r.p.m. to optimize and standardize contact between the cells and conidia. The supernatants were removed and the conidia were counted. Wells were refilled with fresh, pre-warmed culture medium. Cell exposure was terminated at 2, 4, 8 and $24 \mathrm{~h}$. These experiments were performed at least three times under all conditions.

Quantification of conidia ingestion. The internalized conidia were quantified using the fluorescence brightener Blankophor-P-fluessig [4,4' -bis[(4-anilino-6-substituted-1,3,5-trazine-2-yl) amino stilbene2,2'-disulfonic acid], kindly provided by Bayer (Botterel et al., 2008).
The brightener stained only the external conidia. Ten microlitres of the dye was diluted in $1 \mathrm{ml}$ culture medium and $300 \mu \mathrm{l}$ of this dilution was added to the wells and incubated for $10 \mathrm{~min}$ at $37{ }^{\circ} \mathrm{C}$ to stain non-internalized conidia. The wells were washed twice to collect any remaining unattached conidia and to remove the dye. The A549 cells were then lysed with $300 \mu$ distilled water to allow counting of all conidia associated with or ingested by the cells. An Axioskop 40 microscope (Zeiss) with a filter combination including a barrier filter at $420 \mathrm{~nm}$ was used to classify the conidia. When UV light was stimulated below $400 \mathrm{~nm}$, the brightener emitted a very intense bluish, yellowish or white light (Ruchel \& Margraf, 1993). The blue conidia were classified as non-internalized and the non-fluorescent conidia as internalized.

Dexamethasone experiments. A549 cells were also challenged with A. fumigatus conidia in the presence of $10^{-6}$ and $10^{-7} \mathrm{M}$ dexamethasone (Sigma). Dexamethasone was dissolved in $90 \%$ ethanol, diluted in culture medium and added to the A549 cells just after centrifugation of the plates and removal of the supernatant. The growth of A. fumigatus in DMEM at $37{ }^{\circ} \mathrm{C}$ in the presence of $10^{-3}-10^{-7} \mathrm{M}$ dexamethasone was also monitored for effects on fungal growth at $37^{\circ} \mathrm{C}$. Fungal germination was analysed at 4, 8 and $24 \mathrm{~h}$.

mRNA quantification. RNA was extracted using an RNAble kit (Eurobio). Determination of the concentration of nucleic acids was performed using a spectrophotometer (Nanodrop ND 1000) and the concentrations were adjusted to $250 \mathrm{ng} \mu \mathrm{l}^{-1}$. Reverse transcription was carried out in a final volume of $20 \mu \mathrm{l}$ as follows: $1 \mu \mathrm{g}(4 \mu \mathrm{l})$ RNA extract was added to $2 \mu \mathrm{l} 0.1 \mathrm{M}$ dithiothreitol (Invitrogen), $0.5 \mu \mathrm{l}$ Superscript II reverse transcriptase (200 $\mathrm{U}^{-1}$; Invitrogen), $4 \mu \mathrm{l} 5 \times$ first-strand buffer [250 mM Tris/ $\mathrm{HCl}(\mathrm{pH} 8.3), 375 \mathrm{mM} \mathrm{KCl}, 15 \mathrm{mM}$ $\mathrm{MgCl}_{2}$; Invitrogen], $2 \mu \mathrm{l} 5 \mathrm{mM}$ dNTP mix (Amersham Pharmacia), $6 \mu \mathrm{pdN}_{6}$ random hexamers $\left(0.5 \mu \mathrm{g}^{-1}\right.$; Amersham Pharmacia) and

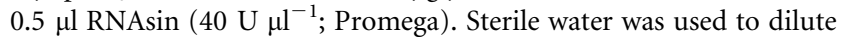
the cDNAs $(1: 20)$ before storing at $-80{ }^{\circ} \mathrm{C}$ until amplification. For each reaction, negative controls without RNA and without reverse transcriptase were carried out.

The primers used are listed in Table 1. Real-time PCR was carried out in a LightCycler 1.5 (Roche) in a $20 \mu \mathrm{l}$ final volume containing $2 \mu \mathrm{l} 10 \times$ Fast Start SYBR Green Buffer (Fast Start SYBR Green kit; Roche Diagnostics), $3 \mathrm{mM} \mathrm{MgCl}_{2}$ for granulocyte-monocyte colony-stimulating factor (GM-CSF; CSF2 gene) and interleukin (IL)-8 (IL-8 gene) and $5 \mathrm{mM} \mathrm{MgCl}$ for tumour necrosis factor (TNF) $-\alpha$ (TNF gene), $50 \mu \mathrm{M}$ sense and antisense primers, $8 \mu \mathrm{lDNA}$ (diluted $1: 20$ ) and sterile water. The thermal cycling conditions were: initial denaturation at $95{ }^{\circ} \mathrm{C}$ for $10 \mathrm{~min}$, followed by 50 cycles of $95{ }^{\circ} \mathrm{C}$ for $15 \mathrm{~s}$ and $65{ }^{\circ} \mathrm{C}$ for $1 \mathrm{~min}$. Quantitative values were obtained from the cycle threshold $\left(C_{\mathrm{t}}\right)$ number. Samples from three independent experiments were analysed in duplicate. The melting curves of each PCR were checked. The presence of contaminating DNA was checked by amplifying an intron of the human albumin gene. Each sample was normalized on the basis of its content compared with two reference mRNAs that were not co-regulated (Bieche et al., 2005). The first gene, P0, also known as 36B4 (GenBank accession no. NM_001002), encodes acid ribosomal phosphoproteins. The second, the TBP gene (GenBank accession no. NM_003194), encodes a component of the DNA-binding protein complex TFIID. The results, expressed as the $N$-fold difference in target gene expression relative to the $\mathrm{P} 0$ or TBP gene (termed $N_{\text {target }}$ ), were determined by the formula $N_{\text {target }}=2^{\Delta C t \text { sample }}$. The $\Delta C_{\mathrm{t}}$ sample was determined by subtracting the mean $C_{\mathrm{t}}$ value of the target gene from the mean $C_{\mathrm{t}}$ value of the TBP or the P0 gene. The $N_{\text {target }}$ values of the samples were subsequently normalized so that the median $N_{\text {target }}$ value of the non-fungus control samples was 1 . 
Table 1. Primers sequences used in the study

\begin{tabular}{|lll|}
\hline Gene target & \multicolumn{1}{c|}{ Sense primer $\left(\mathbf{5}^{\prime} \rightarrow \mathbf{3}^{\prime}\right)$} & \multicolumn{1}{c|}{ Antisense primer $\left(\mathbf{5}^{\prime} \boldsymbol{\rightarrow} \mathbf{3}^{\prime}\right)$} \\
\hline IL-8 $($ IL-8 gene) & CACCGGAAGGAACCATCTCACTGT & TCCTTGGCAAAACTGCACCTTCA \\
TNF- $\alpha$ (TNF gene) & GCCCAGGCAGTCAGATCATCTT & CCTCAGCTTGAGGGTTTGCTACA \\
c-Fos (FOS $)$ & ACCACTCACCCGCAGACTCCT & CCAGGTCCGTGCAGAAGTCCT \\
GM-CSF $($ CSF2) & GAGACACTGCTGCTGAGATGAATG & CAGGTCGGCTCCTGGAGGT \\
P0 & GGCGACCTGGAAGTCCAACT & CCATCAGCACCACAGCCTTC \\
TBP & TGCACAGGAGCCAAGAGTGAA & CACATCACAGCTCCCCACCA \\
Albumin (intron) & GCTGTCATCTCTTGTGGGCTGT & ACTCATGGGAGCTGCTGGTTC \\
\hline
\end{tabular}

Statistical analysis. Data are presented as means \pm SEM of three independent experiments. Statistical analysis was performed using XLSTAT 2007. Differences were considered statistically significant for $P$ $<0.05$. A one-way analysis of variance (ANOVA) test was used to detect significant variations in mRNA levels for each target gene during exposure. A $t$-test was used to detect significant differential mRNA levels with or without dexamethasone.

\section{RESULTS AND DISCUSSION}

Using quantitative PCR, we observed a significant increase in mRNA levels in A549 epithelial cells for all three selected inflammatory mediators (IL-8, TNF- $\alpha$ and GM-CSF) when they were exposed to live A. fumigatus conidia. This increase was observed at $8 \mathrm{~h}$ and continued up to $24 \mathrm{~h}$. This overexpression of mRNA was not observed when the cells were exposed to inactivated A. fumigatus conidia, or to live or inactivated $P$. chrysogenum conidia. The presence of $10^{-7} \mathrm{M}$ dexamethasone prevented the increase in mRNA levels of IL-8, TNF- $\alpha$ and GM-CSF.

\section{Standardization of techniques}

After centrifugation of cell cultures with conidial suspensions, approximately $10 \%$ did not adhere to the A549 cells and were removed. There was no statistical difference between the ingestion rates of conidia for A. fumigatus $(35.3 \pm 3.3 \%)$ and P. chrysogenum $(37.7 \pm 2.0 \%)$ at $4 \mathrm{~h}$ post-exposure.

After RNA extraction, we first checked for contaminating genomic DNA by amplifying an intron of the human albumin gene. The $C_{\mathrm{t}}$ values were always $>37$ and were similar for all of the cDNAs, confirming the absence of DNA contamination. To normalize mRNA expression from different wells, a relative quantification of the target genes and of the endogenous reference $\mathrm{P} 0$ and TBP genes using $\Delta \Delta C_{\mathrm{t}}$ was performed. Because similar results were obtained for both reference genes, only the results standardized with the P0 gene are reported here.

\section{mRNA quantification}

We focused our study on three mediators whose role has been well established in the inflammatory response. The absence of this response is one of the well-known risk factors for IPA, i.e. prolonged neutropenia and steroid therapy. IL-8 is a chemokine involved in both the recruitment of neutrophils and the neutrophil phagocytosis of $A$. fumigatus conidia (Richardson \& Patel, 1995), TNF- $\alpha$ is a cytokine that plays a role in chemokine production and neutrophil activity (Mehrad et al., 1999; Phadke \& Mehrad, 2005) and GM-CSF is a growth factor known to be crucial in the maturation process of granulocytes and macrophages (Walsh et al., 2005). These three mediators are released in response to activation of the $\mathrm{NF}-\kappa \mathrm{B}$ transcriptional complex.

Exposure to live A. fumigatus conidia induced a progressive increase in IL-8, TNF- $\alpha$ and GM-CSF mRNA levels (Fig. 1). A significant overexpression of the mRNA of all three was observed as early as $8 \mathrm{~h}$ post-exposure $(P \leqslant 0.005, P$ $\leqslant 0.002$ and $P \leqslant 0.003$, respectively). This increase was not observed when the cells were exposed to inactivated $A$. fumigatus conidia. No significant variation for any of the three inflammatory mediators was observed when the epithelial cells were exposed to live or inactivated $P$. chrysogenum conidia. Germinating A. fumigatus conidia were observed in A549 cells as early as $8 \mathrm{~h}$ post-exposure. In contrast, with live $P$. chrysogenum conidia and with the inactivated conidia of both species, no germination was observed during the entire $24 \mathrm{~h}$ of the experiment.

We hypothesized that ingestion of conidia by A549 cells could be the triggering factor for the inflammatory response. Overexpression of chemokines and of chemokine receptor genes (IL-8 gene, CCL4, CXCL20 and CXCL2) has been described as early as $2 \mathrm{~h}$ in human monocyte models using cDNA microarray analysis (Cortez et al., 2006). In our study, we were unable to detect any significant increase before $8 \mathrm{~h}$. If conidia ingestion were the triggering event, an inflammatory response would have occurred for both fungal species because the rate of internalized conidia was similar for both species: around $30-40 \%$, as reported previously (Wasylnka \& Moore, 2002).

However, in our study, a sharp increase appeared at the same time as the hyphal growth of $A$. fumigatus, which started after 6-8 h of culture in liquid medium (Manavathu et al., 1999). In addition, exposure to inactivated $A$. fumigatus conidia did not induce any significant modifications of the mRNA levels of the factors studied. Similar results for cytokine production using ELISA were obtained using non-viable fragments of mycelium and inactivated A. fumigatus conidia (Zhang et al., 2005). Recently, infection with hyphae, but not with 


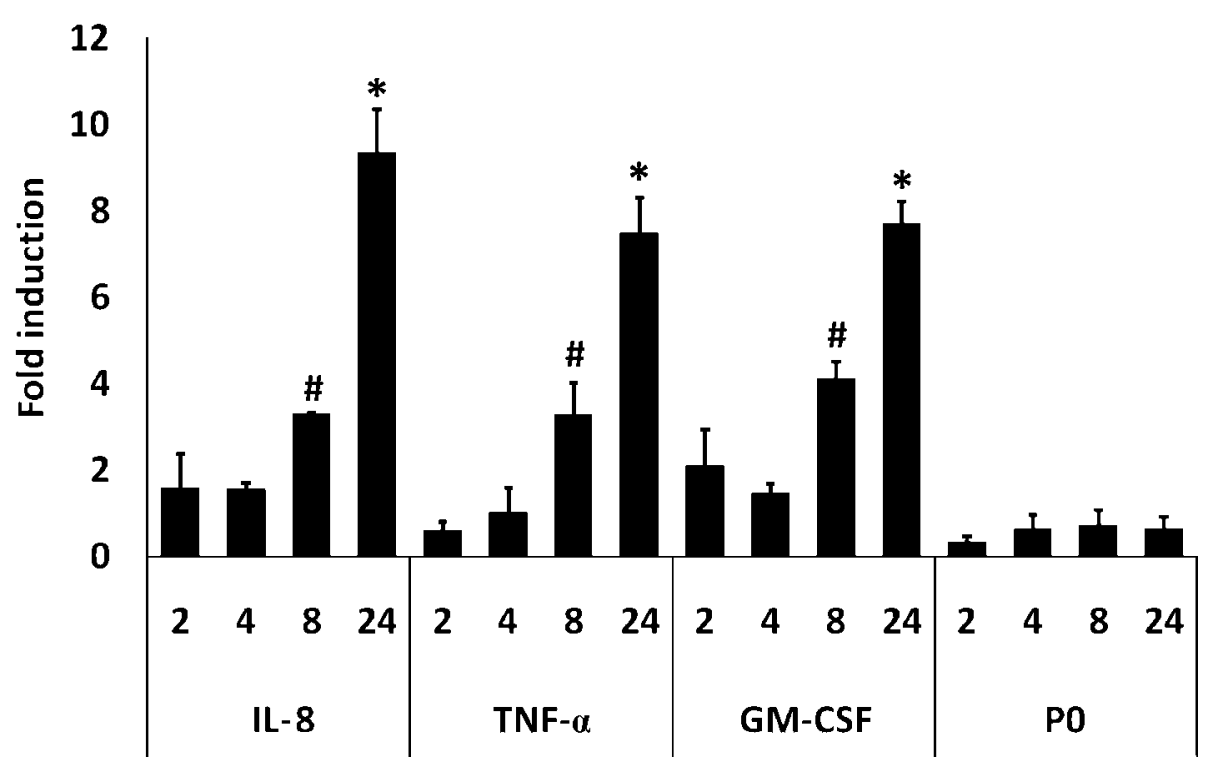

Fig. 1. Standardized mRNA expression of the genes encoding IL-8, TNF- $\alpha$, GM-CSF and PO after exposure of A549 cells to live $A$. fumigatus conidia calculated with the $\Delta \Delta C_{\mathrm{t}}$ method, with $\mathrm{PO}$ as the reference gene. Values were calculated from three independent experiments and gene expression was subsequently normalized against the median values of the uninfected controls. The data are presented as means \pm SEM: significant overexpression at $8 \mathrm{~h}$ (\#) for IL-8 $(P \leqslant 0.005)$, TNF- $\alpha(P \leqslant 0.002)$ and GM-CSF $(P<0.003)$, and at $24 \mathrm{~h}\left(^{*}\right)$ for the three factors $(P \leqslant 0.0001)$, and unchanged expression of the control gene (PO), were analysed by ANOVA.

conidia, was shown to stimulate endothelial cells to synthesize IL-8 and TNF- $\alpha$ in vitro using ELISA (Chiang et al., 2008). We cannot rule out the fact that heating or chemical inactivation may have destroyed epitope structures and heat-labile molecules such as proteases, which are potentially involved in inflammatory signalling. However, our results are in agreement with a recent report on the role of germinating conidia in the innate immune system in vitro and in animal models (Hohl et al., 2005). Conidial swelling is accompanied by an enrichment of $\beta$-glucans on the membrane surface, which triggers inflammatory responses via Dectin-1 recognition (Hohl et al., 2005).

\section{mRNA quantification in the presence of dexamethasone}

Exposure of A549 cells to live conidia of A. fumigatus in the presence of $10^{-6} \mathrm{M}$ (not shown) and $10^{-7} \mathrm{M}$ dexametha-

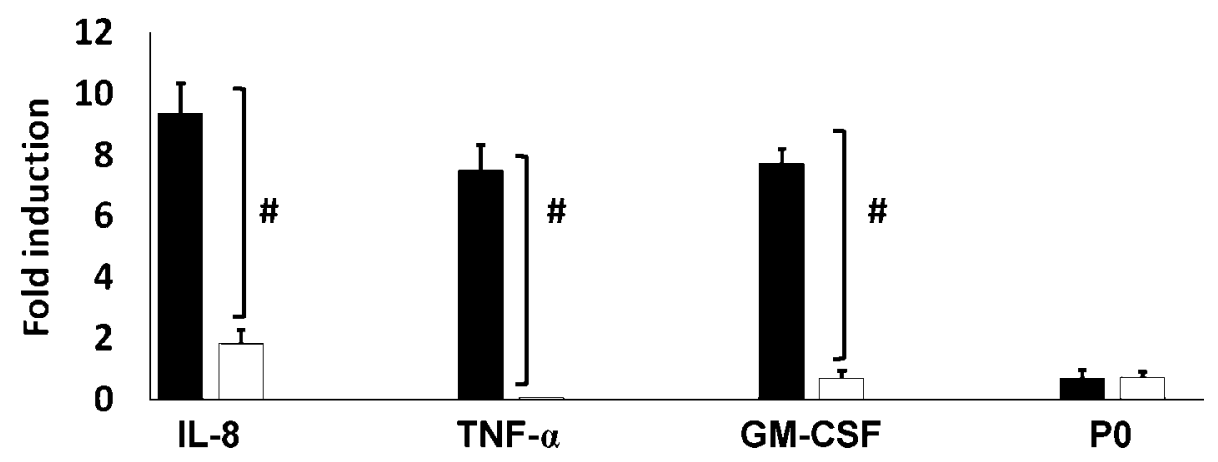

Fig. 2. Standardized mRNA expression of the genes encoding IL-8, TNF- $\alpha$, GM-CSF and P0 after exposure of A549 cells to live $A$. fumigatus conidia with (white columns) and without (black columns) $10^{-7} \mathrm{M}$ dexamethasone using the $\Delta \Delta C_{\mathrm{t}}$ method, with PO as the reference gene. Values were calculated from three independent experiments and gene expression was subsequently normalized against the median values of the uninfected and non-steroid controls. The data are presented as means \pm SEM: absence of mRNA overexpression at $24 \mathrm{~h}(P \leqslant 0.0001$ for each) by $t$-test compared with wells exposed to live conidia of $A$. fumigatus without dexamethasone. The control gene (P0) remained unchanged. 
sone resulted in the absence of overexpression at $8 \mathrm{~h}$ for IL$8(P \leqslant 0.005)$, TNF- $\alpha(P \leqslant 0.002)$ and GM-CSF $(P<0.003)$ and at $24 \mathrm{~h}(P \leqslant 0.01$ for each) (Fig. 2). In addition, dexamethasone at concentrations of $10^{-3}-10^{-7} \mathrm{M}$ did not modify the growth of $A$. fumigatus conidia (data not shown).

Given the significant role that germinating conidia play in IPA, the disappearance of overexpression when the conidia-exposed cells were treated with $10^{-7} \mathrm{M}$ dexamethasone supports the role of steroids as a risk factor for IPA, not only at the macrophage level, but also at the respiratory epithelium level (Nissen \& Yamamoto, 2000). Although the role that steroids play in the NF- $\kappa \mathrm{B}$ pathway of the cells is a probable explanation, we cannot completely rule out the fact that steroids could inhibit the synthesis of a specific fungal compound that could be responsible for the immune stimulation of A549 cells.

These initial results show that germinating A. fumigatus conidia induce overexpression of inflammatory mediators by epithelial cells in the first $24 \mathrm{~h}$ after exposure. Further studies are needed to define in more detail the chemokines, adhesion molecules and other possible pathways involved. However, these results suggest that the respiratory epithelium plays a role in initiating innate immunity to prevent the occurrence of IPA. Our results also confirm that steroids significantly modify the normal inflammatory response of airway cells exposed to A. fumigatus, and this could explain at least in part why steroids are a risk factor for IPA.

\section{ACKNOWLEDGEMENTS}

This work was supported by grants from L'Agence Nationale de la Recherche (no. 0014705), ADEME (no. 0575C0030) and AFSSET (no. ES-2005-012).

\section{REFERENCES}

Asselah, T., Bieche, I., Laurendeau, I., Paradis, V., Vidaud, D., Degott, C., Martinot, M., Bedossa, P., Valla, D. \& other authors (2005). Liver gene expression signature of mild fibrosis in patients with chronic hepatitis $\mathrm{C}$. Gastroenterology 129, 2064-2075.

Bieche, I., Asselah, T., Laurendeau, I., Vidaud, D., Degot, C., Paradis, V., Bedossa, P., Valla, D. C., Marcellin, P. \& Vidaud, M. (2005). Molecular profiling of early stage liver fibrosis in patients with chronic hepatitis $\mathrm{C}$ virus infection. Virology 332, 130-144.

Borger, P., Koeter, G. H., Timmerman, J. A., Vellenga, E., Tomee, J. F. \& Kauffman, H. F. (1999). Proteases from Aspergillus fumigatus induce interleukin (IL)-6 and IL-8 production in airway epithelial cell lines by transcriptional mechanisms. J Infect Dis 180, 1267-1274.

Botterel, F., Gross, K., Ibrahim-Granet, O., Khoufache, K., Escabasse, V., Coste, A., Cordonnier, C., Escudier, E. \& Bretagne, S. (2008). Phagocytosis of Aspergillus fumigatus conidia by primary nasal epithelial cells in vitro. BMC Microbiol 8, 97.

Chiang, L. Y., Sheppard, D. C., Gravelat, F. N., Patterson, T. F. \& Filler, S. G. (2008). Aspergillus fumigatus stimulates leukocyte adhesion molecules and cytokine production by endothelial cells in vitro and during invasive pulmonary disease. Infect Immun 76, 3429 3438 .

Cortez, K. J., Lyman, C. A., Kottilil, S., Kim, H. S., Roilides, E., Yang, J., Fullmer, B., Lempicki, R. \& Walsh, T. J. (2006). Functional genomics of innate host defense molecules in normal human monocytes in response to Aspergillus fumigatus. Infect Immun 74, 2353-2365.

de Hoog, G. S., Guarra, J., Gené, J. \& Figueras, M. J. (2000). Atlas of Clinical Fungi, 2nd edn. Utrecht, The Netherlands: Centraalbureau voor Schimmelcultures/Reus, Spain: Universitat Rovira i Virgili.

Hohl, T. M., van Epps, H. L., Rivera, A., Morgan, L. A., Chen, P. L., Feldmesser, M. \& Pamer, E. G. (2005). Aspergillus fumigatus triggers inflammatory responses by stage-specific $\beta$-glucan display. PLoS Pathog 1, e30.

Huttunen, K., Hyvarinen, A., Nevalainen, A., Komulainen, H. \& Hirvonen, M. R. (2003). Production of proinflammatory mediators by indoor air bacteria and fungal spores in mouse and human cell lines. Environ Health Perspect 111, 85-92.

Kauffman, H. F., Tomee, J. F., van de Riet, M. A., Timmerman, A. J. \& Borger, P. (2000). Protease-dependent activation of epithelial cells by fungal allergens leads to morphologic changes and cytokine production. J Allergy Clin Immunol 105, 1185-1193.

Lin, S. J., Schranz, J. \& Teutsch, S. M. (2001). Aspergillosis casefatality rate: systematic review of the literature. Clin Infect Dis 32, 358-366.

Manavathu, E. K., Cutright, J. \& Chandrasekar, P. H. (1999). Comparative study of susceptibilities of germinated and ungerminated conidia of Aspergillus fumigatus to various antifungal agents. $J$ Clin Microbiol 37, 858-861.

Mehrad, B., Strieter, R. M. \& Standiford, T. J. (1999). Role of TNF- $\alpha$ in pulmonary host defense in murine invasive aspergillosis. J Immunol 162, 1633-1640.

Meier, A., Kirschning, C. J., Nikolaus, T., Wagner, H., Heesemann, J. \& Ebel, F. (2003). Toll-like receptor (TLR) 2 and TLR4 are essential for Aspergillus-induced activation of murine macrophages. Cell Microbiol 5, 561-570.

Nissen, R. M. \& Yamamoto, K. R. (2000). The glucocorticoid receptor inhibits $\mathrm{NF} \kappa \mathrm{B}$ by interfering with serine- 2 phosphorylation of the RNA polymerase II carboxy-terminal domain. Genes Dev 14, 2314 2329.

Phadke, A. P. \& Mehrad, B. (2005). Cytokines in host defense against Aspergillus: recent advances. Med Mycol 43 (Suppl. 1), S173-S176.

Pylkkanen, L., Gullsten, H., Majuri, M. L., Andersson, U., Vanhala, E., Maatta, J., Meklin, T., Hirvonen, M. R., Alenius, H. \& Savolainen, K. (2004). Exposure to Aspergillus fumigatus spores induces chemokine expression in mouse macrophages. Toxicology 200, 255-263.

Richardson, M. D. \& Patel, M. (1995). Stimulation of neutrophil phagocytosis of Aspergillus fumigatus conidia by interleukin-8 and $\mathrm{N}$ formylmethionyl-leucylphenylalanine. J Med Vet Mycol 33, 99-104.

Romani, L. (2004). Immunity to fungal infections. Nat Rev Immunol 4, 1-23.

Ruchel, R. \& Margraf, S. (1993). Rapid microscopical diagnosis of deep-seated mycoses following maceration of fresh specimens and staining with optical brighteners. Mycoses 36, 239-242.

Stephens-Romero, S. D., Mednick, A. J. \& Feldmesser, M. (2005). The pathogenesis of fatal outcome in murine pulmonary aspergillosis depends on the neutrophil depletion strategy. Infect Immun 73, 114125.

Stordeur, P., Poulin, L. F., Craciun, L., Zhou, L., Schandene, L., de Lavareille, A., Goriely, S. \& Goldman, M. (2002). Cytokine mRNA quantification by real-time PCR. J Immunol Methods 259, $55-64$. 
Tai, H. Y., Tam, M. F., Chou, H., Peng, H. J., Su, S. N., Perng, D. W. \& Shen, H. D. (2006). Pen ch 13 allergen induces secretion of mediators and degradation of occludin protein of human lung epithelial cells. Allergy 61, 382-388.

Walsh, T. J., Roilides, E., Cortez, K., Kottilil, S., Bailey, J. \& Lyman, C. A. (2005). Control, immunoregulation, and expression of innate pulmonary host defenses against Aspergillus fumigatus. Med Mycol 43 (Suppl. 1), S165-S172.
Wasylnka, J. A. \& Moore, M. M. (2002). Uptake of Aspergillus fumigatus conidia by phagocytic and nonphagocytic cells in vitro: quantitation using strains expressing green fluorescent protein. Infect Immun 70, 3156-3163.

Zhang, Z., Liu, R., Noordhoek, J. A. \& Kauffman, H. F. (2005). Interaction of airway epithelial cells (A549) with spores and mycelium of Aspergillus fumigatus. J Infect 51, 375-382. 